\title{
Novel Role of Red Wine-Derived Polyphenols in the Prevention of Alzheimer's Disease Dementia and Brain Pathology: Experimental Approaches and Clinical Implications
}

Author

Affiliations

\author{
Giulio Maria Pasinetti
}

${ }^{1}$ Department of Neurology, Mount Sinai School of Medicine, New York, NY, USA

${ }^{2}$ Geriatric Research and Clinical Center, James J. Peters Veterans Affairs Medical Center, Bronx, NY, USA
Key words

polyphenols

- grape

- Alzheimer's disease

- Vitis rotundifolia

- Vitaceae received May 3, 2012

revised July 13,2012

accepted August 22, 2012

\section{Bibliography}

Dol http://dx.doi.org/

10.1055/s-0032-1315377

Published online September 21, 2012

Planta Med 2012; 78 :

1614-1620 @ Georg Thieme

Verlag KG Stuttgart · New York. ISSN 0032-0943

\section{Correspondence}

\section{Giulio Maria Pasinetti, MD,}

PhD

Saunders Family Chair in

Neurology

Department of Neurology

Director Center of Excellence

for Novel Approaches to

Neurotherapeutics

The Mount Sinai School of

Medicine

One Gustave L. Levy Place,

Box 1137

New York, NY 10029-6574

USA

Phone: + 12122417938

Fax: + 12128769042

Giulio.Pasinetti@mssm.edu

\section{Abstract \\ $\nabla$}

Recent studies suggest that by the middle of this century, as many as 14 million Americans will have Alzheimer's disease, creating an enormous strain on families, the health care system and the federal budget. There are still widespread misconceptions about issues related to the prevention and/or treatment of disease pathogenesis, leaving us unprepared to deal with the disease. To address these challenges, several therapeutic approaches are currently under investigation, mainly in an attempt to delay disease onset and eventually slow down its progression. Recent epidemiological evidence has implicated the protective role of dietary polyphenols from grape products against Alzheimer's disease. Furthermore, experimental evidence supports the hypothesis that certain bioactive grape-derived polyphenols may protect against Alzheimer's disease-type

\section{Introduction}

$\nabla$

Alzheimer's disease (AD) is the most common type of dementia in the United States. Victims of AD commonly display a loss of memory, inability to learn new things, loss of language function, deranged perception of space, inability to do calculations, depression, delusions, and other cognitive deficits. AD is ultimately fatal within 5 to 10 years of its onset. Approximately 5 million people in the United States currently have AD [1], with an estimated cost to society of more than $\$ 100$ billion per year. The estimated cost of dealing with $A D$ over the next 40 years is twenty trillion dollars. Up to 14 million people in the United States are projected to be affected by $\mathrm{AD}$ by the middle of this century [1]. To date, there is no cure for AD. The few agents that are approved by the FDA for the treatment of $A D$ have only modest efficacy in terms of modifying clinical symptoms, and none cognitive deterioration, in part by interfering with the generation and assembly of $\beta$-amyloid peptides into neurotoxic oligomeric aggregated species. Brain-targeting polyphenols have been shown to significantly reduce the generation of $\beta$-amyloid peptides in primary cortico-hippocampal neuron cultures, and preliminary results indicate that they may influence neuronal synaptic plasticity. Recent evidence has also implicated the role of certain grape-derived preparations in beneficially modulating tau neuropathology, including reducing tau aggregation. Studies suggest that dietary polyphenolics may benefit Alzheimer's disease by modulating multiple disease-modifying modalities, both $\beta$-amyloid-dependent and independent mechanisms, and provide impetus for the development of polyphenolic compounds for Alzheimer's disease prevention and/or therapy.

appear to affect disease progression or prevention [2]. Scientists are continually exploring novel avenues for preventing or treating this condition.

\section{Alzheimer's Disease Neuropathological Features: Implications for Therapeutic Developments \\ $\nabla$}

While the classification and diagnosis of $A D$ is based on the cognitive behavior of an individual, the roots of the disease lie in the neurological pathology of its victims [3]. The two defining neuropathological features of $\mathrm{AD}$ are abnormal aggregation and deposition of certain toxic peptide fragments known as $\beta$-amyloid ( $A \beta$ ) peptides or tau protein in the brain as, respectively, extracellular neuritic plaques (NP) and intracellular neurofibrillary tangles (NFT) [4]. A $\beta$ peptides are derived from the ubiquitous amyloid precursor protein 


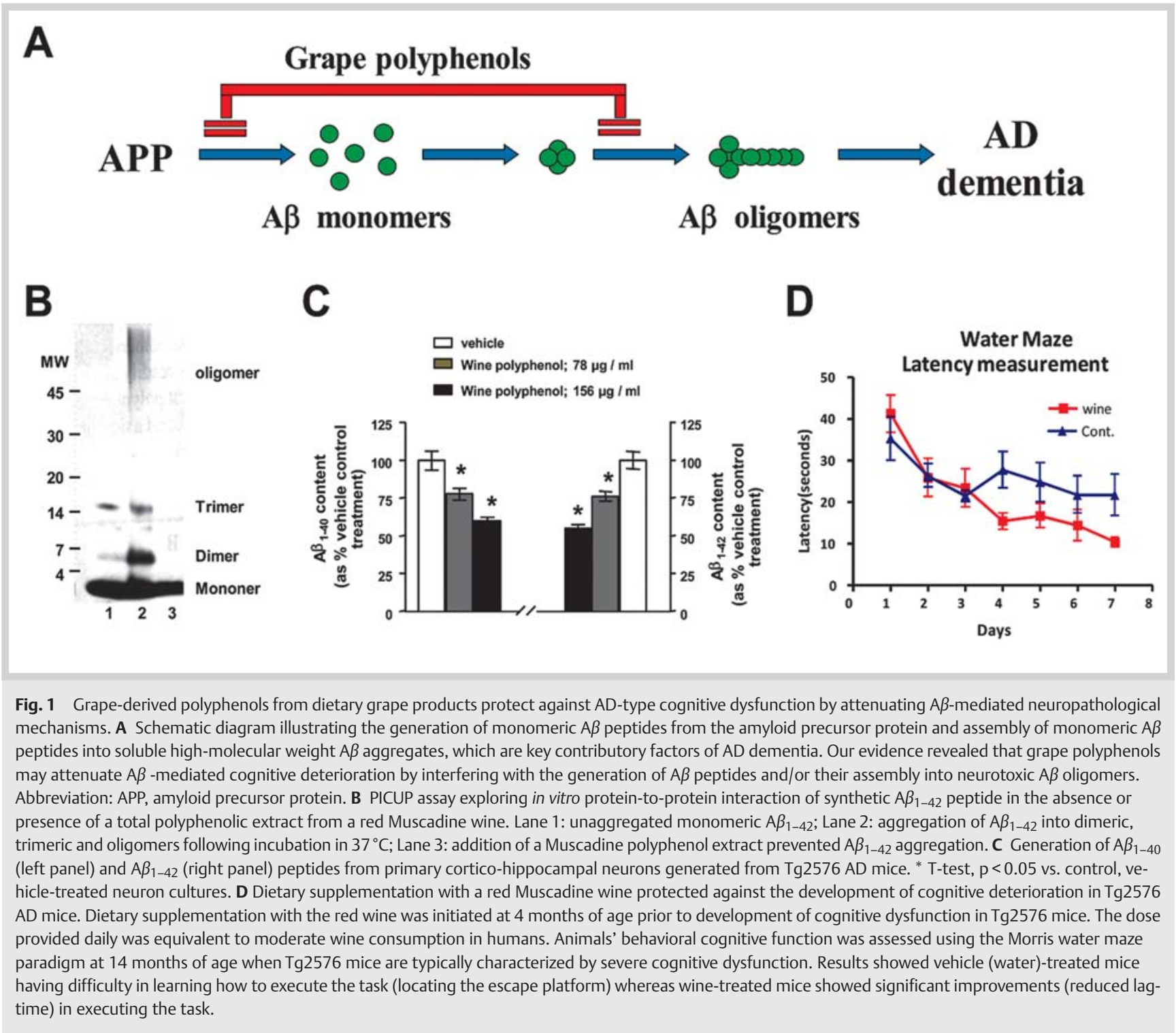

(APP) through amyloidogenic processing by $\beta$ - and $\gamma$-secretases, rather than through non-amyloidogenic cleavage by $\alpha$-secretase. In humans, genetic mutations leading to $A \beta$ neuropathology in at least one of three genes, namely APP, presenilin 1 and presenilin 2 , are causally linked to early onset AD cases and are associated with $\mathrm{AD}$ dementia $[5,6]$. In experimental animal models, these same mutations also accelerate $A \beta$ deposition and cognitive deterioration [7]. Based on this, major efforts are focused on developing pharmacological strategies that delay the initiation and/or slow the progression of $A \beta$-mediated neuropathological responses. Recent evidence from experimental AD mouse models indicates that the accumulation of soluble high-molecular weight oligomeric $A \beta$ species in the brain, rather than deposition of NP per se, may be specifically related to spatial memory reference deficits [8-12].

Despite strong genetic data arguing that $A \beta$ neuropathology is sufficient to cause $\mathrm{AD}$ [13], progressive cognitive decline and neuron and synapse loss in $\mathrm{AD}$ are best correlated with tau neuropathology [14]. In the AD brain, tau proteins, particularly hyperphosphorylated tau, are found aggregated into progressively larger polymeric species that are ultimately deposited as insolu- ble NFTs [15]. NFTs themselves are not necessarily the tau species inducing neurotoxicity $[16,17]$. A predominant theory of taumediated neurodegeneration is based on a "toxic gain of function" model, in which abnormally phosphorylated tau promotes sequestration of both hyperphosphorylated and normal tau from microtubules, leading to microtubule instability and alterations of microtubule-mediated processes, including abnormalities in axon transport, among others [18].

These considerations strongly suggest that reducing the accumulation of soluble oligomeric $A \beta$ peptides and tau species in the brain, as opposed to dissociating or preventing NP and/or NFT formation or their depositions, may be a more productive approach to AD therapy. As discussed in more detail below, we recently demonstrated for the first time that dietary supplementation with red wines equivalent to moderate wine consumption in humans effectively attenuates the development of $A \beta$-mediated neuropathology and cognitive dysfunction in a mouse model of AD. Moreover, our evidence demonstrates that the grape-derived polyphenolics commonly found in red wines may also modulate tau-mediated neuropathology responses ( Fig. 1). 
<smiles>Oc1ccccc1</smiles>

phenol<smiles>O=C1CC(c2ccc(O)cc2)Oc2cc(O)cc(O)c21</smiles>

naringenin (flavanones)<smiles>O=c1oc2cc(O)ccc2c2oc3cc(O)ccc3c12</smiles>

coumestrol (couestans)<smiles></smiles>

anthocyanidins

(cyanidin)<smiles>O=c1cc(-c2ccc(O)c(O)c2)oc2cc(O)cc(O)c12</smiles>

luteolin

(flavones)

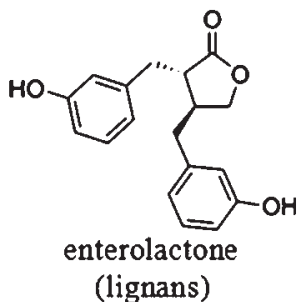<smiles>Oc1cc(O)c2c(c1)O[C@H](c1ccc(O)c(O)c1)C(O)C2</smiles>

catechin

(flavanols)<smiles>O=c1c(-c2ccc(O)cc2)coc2cc(O)cc(O)c12</smiles>

genistein (isoflavones)<smiles>O=c1c(O)c(-c2cc(O)c(O)c(O)c2)oc2cc(O)cc(O)c12</smiles>

myricetin

(flavonols)<smiles>Oc1ccc2c(c1)O[C@H](c1ccc(O)c(O)c1)[C@H](O)[C@H]2c1c(O)cc(O)c2c1O[C@H](c1ccc(O)c(O)c1)[C@@H](O)C2</smiles>

Proanthocyanidin B1 (proanthocyanidins)<smiles>Oc1ccc(/C=C/c2cc(O)cc(O)c2)cc1</smiles>

Fig. 2 Examples of polyphenols by class. Shown are chemical structures of phenol and representative bioflavonoids (cyanidin, flavanols, flavonols, fla- vanones, flavones, isoflavones, and proanthocyanidins), couestans, lignans, and stilbenoids.

\section{Red Wine-Derived Polyphenols and Alzheimer's Disease}

While genetic factors are highly relevant in early-onset AD cases, their significance diminishes in late-onset sporadic AD cases, which is the most common form of AD [2]. Nongenetic factors, including modifiable lifestyle and dietary regimens such as moderate consumption of alcoholic beverages, are receiving increasing attention in AD research, especially in light of the recent epidemiological studies indicating that moderate wine consumption may influence the relative risk for AD clinical dementia [19]. Little is known about the beneficial role of red wine in AD dementia onset. The neuroprotective efficacy of red wine is typically attributed to the antioxidant activities of polyphenols in the wine. To explore how red wines might benefit AD, we tested whether dietary supplementation with red wines may beneficially modulate AD phenotypes in the Tg2576 AD mouse model [20]. Recapitulating select features of $\mathrm{AD}, \mathrm{Tg} 2576$ mice are characterized by progressive development of $A \beta$ neuropathology and cognitive decline with increasing age.

\section{Potential Benefits of Moderate Consumption of Red Wine and Other Dietary Grape Polyphenol Products in Alzheimer's Disease}

Polyphenols are members of a very large family of plant-derived compounds containing one or more phenolic group. Thousands of polyphenols have been identified to date, including bioflavo- noids (anthocyanins, flavanols, favonols, favones, flavanones, isofavones and proanthocyanins), coumestans, ligans and stilbenoids. To illustrate, Fig. 2 presents examples of polyphenol structures by class. The content and composition of polyphenols among dietary grape products (and other plant products) vary tremendously depending on the type/source of plants used in the product, conditions under which these plants were grown, harvested and processed into specific dietary products, and how these products are stored and used [21-29].

Another key consideration for developing dietary polyphenols as novel dietary/supplemental approaches for preventing and/or treating $\mathrm{AD}$ dementia and brain pathology is that almost all of the bioactive polyphenols found in the brain are not directly available through our food supply, but are derived from Phase II xenobiotic metabolism of precursor, dietary polyphenols [30]. The bioavailability of polyphenols is a complex process known to be influenced by several factors including the food composition, dietary patterns, the dose and dose regime as well as the nutritional and pathophysiological status of an individual [30-38]. Many publications have discussed the potential role of dietary grape polyphenols in treating AD. Unfortunately, almost all of these are based on in vitro studies using the aglycone form of polyphenols, which are generally commercially available but are typically not physiologically relevant. Studies from our group [34] and from others [39] have shown that almost all dietary grape-derived polyphenols in circulating blood and, more importantly, in the brain [34], which is the key target tissue for AD interventions, are not in the aglycone form but rather in metabolically derivatized forms. Thus, follow-up bioactivity studies ex- 


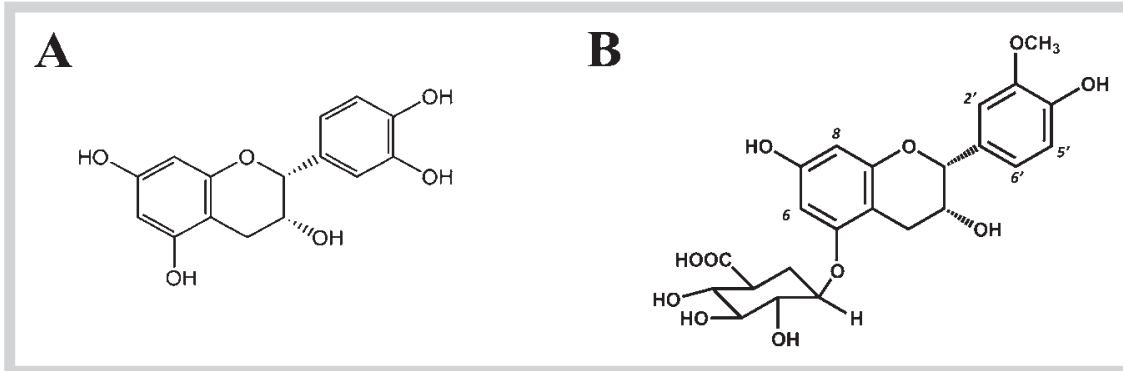

Fig. 3 Chemical structures of epicatechin and methyl-epicatechin glucuronide. A Epicatechin and B 3'-O-methyl-epicatechin-5-O- $\beta$-glucuronide, a bioactive metabolic epicatechin derivative that we recently reported, penetrates into brain tissue and promotes LTP responses in the brain [40].

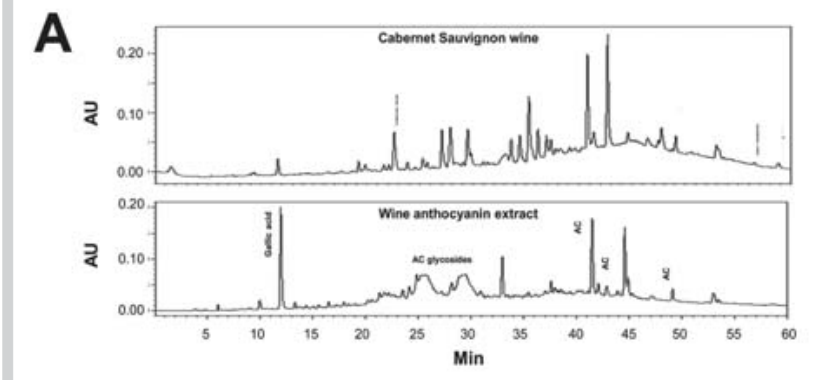

B

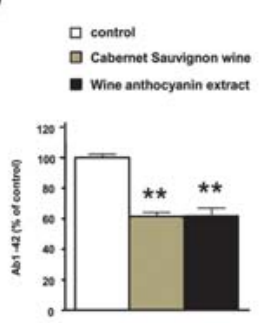

Fig. 4 Anthocyanin polyphenol components of Cabernet Sauvignon are bioactive in terms of inhibiting $A \beta$ generation. We subfractionated total polyphenolics from the red Cabernet Sauvignon wine into multiple preparations with different polyphenolic composition profiles. A Shown are HPLC analysis of total polyphenolics from Cabernet Sauvignon (top panel) and a subfraction comprised primarily of anthocyanin components (bottom panel). Abbreviation: AC, anthocyanin. B Generation of $A \beta_{1-40}$ peptide by primary cortico-hippocampal neuron cultures from $\mathrm{Tg} 2576$ mice in the presence of vehicle (control) or presence of total polyphenols from the wine or in the presence of the anthocyanin polyphenol subfraction. ploring the potential beneficial role of grape-derived polyphenols in AD should be conducted using specific metabolites that are accumulated in the brain. For example, we have recently identified selected epicatechin glucuronide derivatives from a grape seed polyphenolic extract that are capable of penetrating the brain [34] and potentially attenuating $\mathrm{AD}$, in part by promoting neuroplasticity processes [40]. The structure of this bioactive epicatechin glucuronide as well as the structure of epicatechin, its parent compound, is illustrated in $\bullet$ Fig. 3.

Consistent with epidemiological evidence implicating the protective role of dietary polyphenols from grape products against AD [19], our preclinical studies have demonstrated that dietary supplementation with a grape seed polyphenol extract [41], or moderate consumption of red wines $[42,43]$ containing high contents of grape polyphenols, is effective in attenuating the onset and progression of $\mathrm{A} \beta$-mediated $\mathrm{AD}$-type neuropathology and cognitive deterioration in transgenic mouse models of $A D$. As schematically shown in $\odot$ Fig. $1 \mathrm{~A}, \mathrm{~A} \beta$ peptides are derived from the ubiquitous protein APP through amyloidogenic processing by $\beta$ - and $\gamma$-secretases rather than through non-amyloidogenic cleavage by $\alpha$-secretase. Monomeric $A \beta$ peptides (e.g., $A \beta_{1-40}$ or $A \beta_{1-42}$ peptides) tend to assemble into soluble, high-molecular weight neurotoxic $A \beta$ aggregates that are key contributory factors to AD dementia. Our evidence has demonstrated that polyphenolic components from grape products may protect against $\mathrm{AD}$ dementia, in part by reducing $A \beta$-mediated neurotoxic mechanisms. Mechanistically, we found that grape-derived polyphenols may modulate $A \beta$ toxicity by either reducing the generation of $A \beta$ peptides from the amyloid precursor protein and/or by interfering with the assembly of $A \beta$ peptides into highmolecular weight neurotoxic $A \beta$ aggregated species ( $\odot$ Fig. $1 \mathrm{~A}$ ). For example, using a PICUP assay [44] we demonstrated that polyphenolic components from a red Muscadine wine, made from Vitis rotundifolia (Vitaceae), significantly interfere with $A \beta$ protein-to-protein interactions critical for the initial assembly of monomeric $A \beta$ peptides into increasingly large aggregated species ( $\bullet$ Fig. 1B). In another example, we showed that treatment with a polyphenolic extract from another red wine (Cabernet Sauvignon) significantly reduced the generation of $A \beta_{1-40}$ ( $\odot$ Fig. $1 C$, left panel) and $A \beta_{1-42}(\odot$ Fig. $1 C$, right panel) in a dose-dependent manner in primary cortico-hippocampal cultures generated from the Tg2576 transgenic AD mouse model. As an example illustrating the efficacy of dietary supplementation with grape products in protecting against cognitive deterioration, 1 Fig. 1 D shows that dietary supplementation with the Muscadine wine, equivalent to moderate consumption in humans, significantly attenuats the development of cognitive deterioration in the Tg2576 AD mouse model.

Collectively, we have studied two unrelated red wines, a Cabernet Sauvignon and a Muscadine wine, for their efficacy in modulating AD phenotypes in the Tg2576 transgenic AD mouse model [42, 43] and found that both wines are effective in attenuating $A \beta$ mediated neuropathology and cognitive dysfunction. Moreover, our evidence suggests that polyphenols from the two wines benefit $A \beta$-mediated phenotypes through different mechanisms polyphenols from Cabernet Sauvignon wine are effective in reducing the generation of $A \beta$ peptides [42] while polyphenols from the Muscadine wine attenuate $A \beta$ aggregation, but have no impact on $A \beta$ generation [43]. The two wines are characterized by a distinct composition of polyphenolic compounds. Thus, our studies revealed that distinct and varied polyphenolic compounds from red wines and other dietary sources may be bioavailable at the organism level and may beneficially modulate $\mathrm{AD}$ phenotypes through multiple $\mathrm{A} \beta$-related mechanisms.

Ongoing studies aimed at identifying which of the polyphenols in the Cabernet Sauvignon and in the Muscadine wine might be responsible for $\mathrm{A} \beta$-lowering and anti- $\mathrm{A} \beta$ aggregation activities, respectively. Outcomes will provide critical information for the 


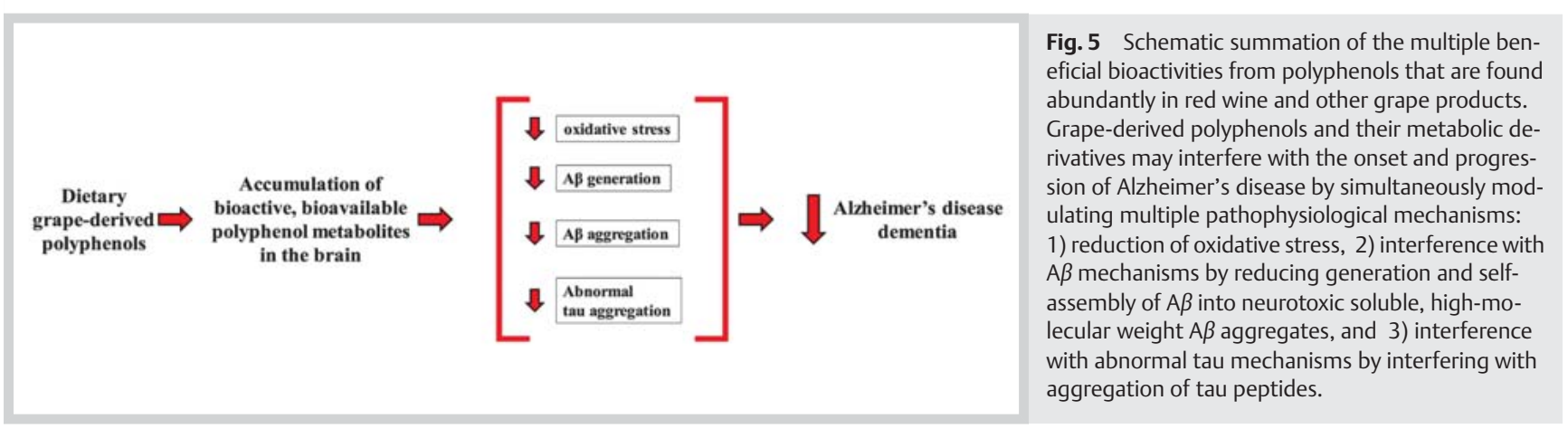

identification of specific wines and other dietary products that might prove to be effective in AD prevention and therapy. Accumulating evidence suggests that resveratrol, a naturally occurring polyphenolic compound that is associated with beneficial effects on aging, metabolic disorders, inflammation and cancer in animal models [45] and that is found in varying concentrations in red wine and many food products, may enhance $A \beta$ clearance by promoting intracellular proteosome activity in vitro [46]. However, the role of resveratrol in our study on Cabernet Sauvignon treatment in Tg2576 mice [42] is not clear since the Cabernet Sauvignon used had only $0.2 \mathrm{mg} / \mathrm{L}$ resveratrol, a concentration 10-fold lower than the minimal effective concentration shown to promote $A \beta$ clearance in vitro [46]. To gather insights into the specific dietary grape-derived polyphenol(s) that might be relevant to $A D$, we subfractionated polyphenols from bioactive grape products (e.g., red wine and grape seed extract) containing increasingly less complicated polyphenol compositions and conducted in vitro and in vivo studies for exploiting potential beneficial AD-modifying activities. We fractionated total polyphenols from the red Cabernet Sauvignon wine and found that the $A \beta$ lowering activity of Cabernet Sauvignon can be attributed to its anthocyanin polyphenolic components ( $\bullet$ Fig. 4).

\section{Grape Polyphenols Beneficially Modulate Tau-Mediated Neuropathological Responses $\nabla$}

In recent studies, we found that grape seed polyphenolic extracts (GSPE) are capable of interfering with tau-mediated toxicity by interfering with the abnormal aggregation of tau [47-49]. We used both the TMHT [48] and JNPL3 [49] mutant tau mouse models of $A D$, which overexpress the human TAU441 gene bearing missense mutations V337M and R406W and express human tau protein containing the P301L mutation, to test the efficacy of GSPE in interfering with dementia resulting from abnormal tau functions. We found that dietary supplementation with GSPE in these tau mouse models effectively reduced the severity of abnormal tau aggregation and neuropathology in the brain [47-49]. While ongoing studies are evaluating the efficacy of grape-derived preparations in preserving cognitive function in these tau mouse models, our data suggest that GSPE might also protect against AD and other dementias in which tau neuropathology is a major contributory factor in the development of cognitive impairment.

\section{Dietary Grape-Derived Bioactive Polyphenolic Components in Alzheimer's Disease Dementia $\checkmark$}

Evidence from our studies strongly supports the hypothesis that moderate red wine consumption might provide preventive and/ or therapeutic value in AD. Our experimental evidence suggests that in addition to providing antioxidant activities, polyphenols from red wines and other grape products may also benefit AD by directly modulating $A \beta$ - as well as tau-related pathological mechanisms in the brain ( Fig. 5). Based on our observation that multiple dietary grape products with distinct polyphenolic component compositions effectively protect against the onset and progression of $\mathrm{AD}$ phenotypes, we hypothesize that additional dietary products containing similar polyphenol forms as grapes, including other red wines, cocoa, tea, apple and berries, might also provide beneficial disease-modifying activities in AD.

There is an urgent need for additional studies in order to identify specific bioactive polyphenolics and corresponding polyphenolic metabolic derivatives from red wines or other grape-derived dietary products that are physiologically bioavailable in target tissues and in order to characterize the mechanisms of action of these bioactive polyphenols. Such information will provide the rational basis for developing selective bioactive dietary polyphe$\mathrm{nol}(\mathrm{s})$ as lead compounds for clinical testing in AD. Moreover, this information will facilitate the selection of food sources enriched in targeted bioactive polyphenols that ultimately could be incorporated as key components in the development of dietary guidelines for AD prevention and/or management.

\section{Acknowledgement \\ $\nabla$}

This material is the result of work supported in part with resources and the use of facilities at the James J. Peters Veterans Affairs Medical Center, Bronx, NY. In addition, Dr. Pasinetti holds a Career Scientist Award in the Research and Development unit and is the Director of the Basic and Biomedical Research and Training Program, GRECC, James J. Peters Veterans Affairs Medical Center. We also acknowledge that the contents of this manuscript do not represent the views of the U.S. Department of Veterans Affairs or the United States Government.

\section{Conflict of Interest $\nabla$}

There are no relevant conflicts of interest to be reported. 


\section{References}

1 Alzheimer's Association. 2008 Alzheimer's disease facts and figures. Alzheimer's \& Dementia 2008; 4: 110-133

2 Cummings JL. Treatment of Alzheimer's disease: current and future therapeutic approaches. Rev Neurol Dis 2004; 1: 60-69

3 Duyckaerts C, Delatour B, Potier MC. Classification and basic pathology of Alzheimer's disease. Acta Neuropathol 2009; 118: 5-36

4 Davies P, Koppel J. Mechanism-based treatment for Alzheimer's disease. Dialogues Clin Neurosci 2009; 11: 159-169

5 Bertram L, Tanzi RE. Thirty years of Alzheimer's disease genetics: the implications of systematic meta-analyses. Nat Rev Neurosci 2008; 9: 768778

6 Scheuner D, Eckman C, Jensen M, Song X, Citron M, Suzuki N, Bird TD, Hardy J, Hutton M, Kukull W, Larson E, Levy-Lahad E, Viitanen M, Peskind E, Poorkaj P, Schellenberg G, Tanzi R, Wasco W, Lannfelt L, Selkoe $D$, Younkin S. Secreted amyloid beta-protein similar to that in the senile plaques of Alzheimer's disease is increased in vivo by the presenilin 1 and 2 and APP mutations linked to familial Alzheimer's disease. Nat Med 1996; 2: 864-870

7 Duff K, Eckman C, Zehr C, Yu X, Prada CM, Perez-tur J, Hutton M, Buee L, Harigaya Y, Yager D, Morgan D, Gordon MN, Holcomb L, Refolo L, Zenk B, Hardy J, Younkin S. Increased amyloid- $\beta 42(43)$ in brains of mice expressing mutant presenilin 1. Nature 1996; 383: 710-713

8 Cleary JP, Wash DM, Hofmeister JJ, Shankar M, Kuskowski MA, Selkoe DJ, Ashe $\mathrm{KH}$. Natural oligomers of the amyloid-beta protein specifically disrupt cognitive function. Nat Neurosci 2005; 8: 79-84

9 Jacobsen JS, Wu CC, Redwine JM, Comery TA, Arias R, Boxlby M, Martone $R$, Morrison JH, Pangalos MN, Reinhart PH, Bloom FE. Early-onset behavioral and synaptic deficits in a mouse model of Alzheimer's disease. Proc Natl Acad Sci USA 2006; 103: 5161-5166

10 Klyubin I, Walsh DM, Lemere CA, Cullen WK, Shankar GM, Betts V, Spooner ET, Jiang L, Anwyl R, Selkoe DJ, Rowan MJ. Amyloid beta protein immunotherapy neutralizes Abeta oligomers that disrupt synaptic plasticithy in vivo. Nat Med 2005; 11: 556-561

11 Lesne S, Koh MT, Kotilinek L, Kayed R, Glabe CG, Yang A, Gallagher M, Ashe $\mathrm{KH}$. A specific amyloid-beta protein assembly in the brain impairs memory. Nature 2005; 440: 352-357

12 Walsh DM, Klyubin I, Fadeeva JV, Cullen WK, Anwyl R, Wolfe MS, Rowan MJ, Selkoe DJ. Naturally secreted oligomers of amyloid beta protein potently inhibit hippocampal long-term potentiation in vivo. Nature 2002; 416: 535-539

13 Hardy J, Selkoe DJ. The amyloid hypothesis of Alzheimer's disease: progress and problems on the road to therapeutics. Science 2002; 297: 353-356

14 Goedert M. Tau protein and the neurofibrillary pathology of Alzheimer's disease. Ann NY Acad Sci 1996; 77: 121-131

15 Sahara N, Maeda S, Takashima A. Tau oligomerization: a role for tau aggregation intermediates linked to neurodegeneration. Curr Alzheimer Res 2008; 5: 591-598

16 Berger Z, Roder H, Hanna A, Carlson A, Rangachari V, Yue M, Wszolek Z, Ashe K, Knight J, Dickson D, Andorfer C, Rosenberry TL, Lewis J, Hutton M, Janus $C$. Accumulation of pathological tau species and memory loss in a conditional model of tauopathy. J Neurosci 2007; 27: 3650-3652

17 Santacruz K, Lewis J, Spires T, Paulson J, Kotilinek L, Ingelsson M, Guimaraes A, Deture M, Ramsden M, McGowan E, Forster C, Yue M, Orne J, Janus C, Mariash A, Kuskowski M, Hyman B, Hutton M, Ashe KH. Tau suppression in a neurodegenerative mouse model improves memory function. Science 2005; 309: 476-481

18 Sorrentino G, Bonavita V. Neurodegeneration and Alzheimer's disease: the lesson from tauopathies. Neurol Sci 2007; 28: 63-71

19 Ramesh BN, Rao TS, Prakasam A, Sambamurti K, Rao KS. Neuronutrition and Alzheimer's disease. J Alzheimers Dis 2010; 19: 1123-1139

20 Hsiao K, Chapman P, Nilsen S, Eckman C, Harigaya Y, Younkin S, Yang F, Cole $G$. Correlative memory deficits. A $\beta$ elevation, and amyloid plaques in transgenic mice. Science 1996; 274: 99-102

21 Brouillard R, George F, Fougerousse A. Polyphenols produced during red wine ageing. Biofactors 1997; 6: 403-410

22 Cantos E, Espin JC, Tomas-Barberan FA. Varietal differences among the polyphenol profiles of seven table grape cultivars studied by LC-DAD-MS-MS. J Agric Food Chem 2002; 50: 5691-5696

23 De La Hera Orts ML, Martinez-Cutillas A, Lopez Roca JM, Perez-Prieto E, Gomez-Plaze E. Effect of deficit irrigation on anthocyanin content of Monastrell grapes and wines. J Int Sci Vigne Vin 2005; 39: 47-55
24 Lee JE, Hwang GS, Van Den BF, Lee CH, Hong YS. Evidence of vintage effects on grape wines using $1 \mathrm{H}$ NMR-based metabolomic study. Anal Chim Acta 2009; 648: 71-76

25 Manach C, Scalbert A, Morand C, Rémésy C, Jiménez L. Polyphenols: food sources and bioavailability. Am J Clin Nutr 2004; 79: 727-747

26 Pérez-Jiménez J, Neveu V, Vos F, Scalbert A. Identification of the 100 richest dietary sources of polyphenols: an application of the Phenol-Explorer database. Eur J Clin Nutr 2010; 64 (Suppl. 3): S112-S120

27 Radovanovic BC, Radovanovic AN, Souquet JM. Phenolic profile and free radical-scavenging activity of Cabernet Sauvignon wines of different geographical origins from the Balkan region. J Sci Food Agric 2010; 90: $2455-2461$

28 Yokotsuka K, Nagao A, Nakazawa K, Sato M. Changes in anthocyanins in berry skins of Merlot and Cabernet Sauvignon grapes grown in two soils modified with limestone or oyster shell versus a native soil over two years. AmJ Enol Viticult 1999; 50: 1-12

29 Xu Y, Simon JE, Welch C, Wightman JD, Ferruzzi MG, Ho L, Passinetti GM, $W u$ Q. Survey of polyphenol constituents in grapes and grape-derived products. J Agric Food Chem 2011; 59: 10586-10593

30 Barnes S, Prasain J, D'Alessandro T, Arabshahi A, Botting N, Lila MA, Jackson $G$, Janle EM, Weaver CM. The metabolism and analysis of isoflavones and other dietary polyphenols in foods and biological systems. Food Funct 2011; 2: 235-244

31 Wu Z, Ming J, Gao R, Wang Y, Liang Q Yu H, Zhao G. Characterization and antioxidant activity of the complex of tea polyphenols and oat $\beta$-glucan. J Agric Food Chem 2011; 59: 10737-10746

32 Semalty A, Semalty M, Rawat MS, Franceschi F. Supramolecular phospholipids-polyphenolics interactions: the PHYTOSOME strategy to improve the bioavailability of phytochemicals. Fitoterapia 2010; 81: 306-314

33 Monagas M, Urpi-Sarda M, Sánchez-Patán F, Llorach R, Garrido I, GómezCordovés C, Andres-Lacueva C, Bartolomé B. Insights into the metabolism and microbial biotransformation of dietary flavan-3-ols and the bioactivity of their metabolites. Food Funct 2010; 1 : 233-253

34 Ferruzzi MG, Lobo JK, Janle EM, Cooper B, Simon JE, Wu QL, Welch C, Ho L, Weaver C, Pasinetti GM. Bioavailability of gallic acid and catechins from grape seed polyphenol extract is improved by repeated dosing in rats: implications for treatment in Alzheimer's disease. J Alzheimers Dis 2009; 18: 113-124

35 Yang CS, Sang S, Lambert JD, Lee MJ. Bioavailability issues in studying the health effects of plant polyphenolic compounds. Mol Nutr Food Res 2008; 52 (Suppl. 1): S139-S151

36 Galli F. Interactions of polyphenolic compounds with drug disposition and metabolism. Curr Drug Metab 2007; 8: 830-838

37 Silberberg M, Besson C, Manach C, Remesy C, Morand C. Influence of dietary antioxidants on polyphenol intestinal absorption and metabolism in rats. J Agric Food Chem 2006; 54: 3541-3546

38 Lambert JD, Hong J, Kim DH, Mishin VM, Yang CS. Piperine enhances the bioavailability of the tea polyphenol (-)-epigallocatechin-3-gallate in mice. J Nutr 2004; 134: 1948-1952

39 Forester SC, Waterhouse AL. Metabolites are key to understanding health effects of wine polyphenolics. J Nutr 2009; 139: 1824S-1831S

40 Wang J, Ferruzzi MG, Ho L, Blount J, Janle EM, Gong B, Pan Y, Gowda GA, Raftery D, Arrieta-Cruz I, Sharma V, Cooper B, Lobo J, Simon JE, Zhang C, Cheng A, Qian X, Ono K, Teplow DB, Pavlides C, Dixon RA, Pasinetti GM. Brain-targeted proanthocyanidin metabolites for Alzheimer's disease treatment. J Neurosci 2012; 32: 5144-5150

41 Wang J, Ho L, Zhao W, Ono K, Rosensweig C, Chen L, Humala N, Teplow $D B$, Pasinetti GM. Grape-derived polyphenolics prevent Abeta oligomerization and attenuate cognitive deterioration in a mouse model of Alzheimer's disease. J Neurosci 2008; 28: 6388-6392

42 Wang J, Ho L, Zhao Z, Seror I, Humala N, Dickstein DL, Thiyagarajan M, Percival SS, Talcott ST, Pasinetti GM. Moderate consumption of Cabernet Sauvignon attenuated beta-amyloid neuropathology in a mouse model of Alzheimer/s disease. FASEB J 2006; 20: 2313-2320

43 Ho L, Chen LH, Wang J, Zhao W, Talcott ST, Ono K, Teplow D, Humala N, Cheng A, Percival SS, Ferruzzi M, Janle E, Dickstein DL, Pasinetti GM. Heterogeneity in red wine polyphenolic contents differentially influences Alzheimer's disease-type neuropathology and cognitive deterioration. J Alzheimers Dis 2009; 16: 59-72

44 Bitan G, Lomakin A, Teplow DB. Amyloid beta-protein oligomerization: prenucleation interactions revealed by photo-induced cross-linking of unmodified proteins. J Biol Chem 2001; 276: 35176-35184

45 Pasinetti GM, Wang J, Marambaud P, Ferruzzi M, Gregor P, Knable LA, Ho $L$. Neuroprotective and metabolic effects of resveratrol: therapeutic 
implications for Huntington's disease and other neurodegenerative disorders. Exp Neurol 2011; 232: 1-6

46 Marambaud P, Zhao H, Davies P. Resveratrol promotes clearance of Alzheimer's disease amyloid- $\beta$ peptides. J Biol Chem 2005; 280: 3737737382

47 Ho L, Pasinetti GM. Polyphenolic compounds for treating neurodegenerative disorders involving protein misfolding. Expert Rev Proteomics 2010; 7: 579-589
48 Wang J, Santa-Maria I, Ho L, Ksiezak-Reding H, Ono K, Teplow DB, Pasinetti GM. Grape derived polyphenols attenuate tau neuropathology in a mouse model of Alzheimer's disease. J Alzheimers Dis 2010; 22: 653661

49 Santa-Maria I, Diaz-Ruiza C, Ksiezak-Reding H, Chen A, Ho L, Wang J, Pasinetti GM. GSPE interferes with tau aggregation in vivo: implication for treating tauopathy. Neurobiol Aging 2012; 33: 2072-2081
Please note: This article was changed according to the following erratum on 5 Dec. 2012: Fig. 3 has been corrected, Panel B is now an epicatechin, as it is stated in the legend.
Please note: This article was changed according to the following corrigendum on 11 March, 2015: Affiliation \#2 and Acknowledgements were added. 